\title{
What is stopping you from becoming an implant dentist?
}
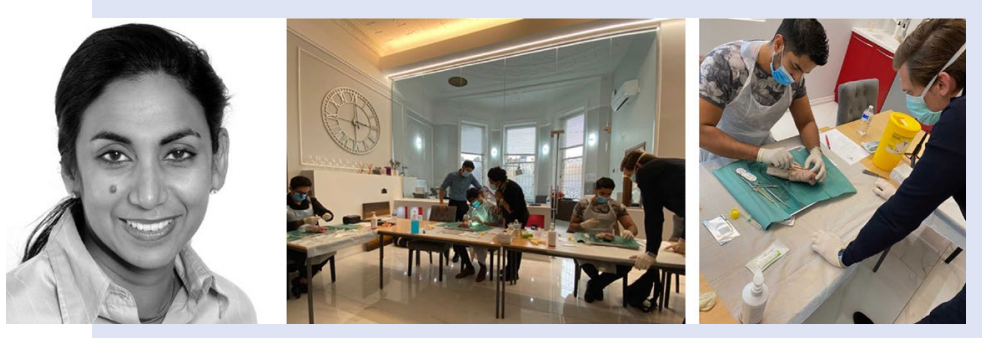

The answer is: nothing!

One to One Dental Education offers world-class programmes in placing implants.
You will be taught by experts, in a custom-built facility in London, with training overseen by clinician and lecturer Dr Fazeela Khan-Osborne, known for her experience in this area.

When you embark on a course with One to One Dental Education, you gain mentors that will continue to guide and inspire you, long after the final day has ended.

This is limitless learning that will guide you on a journey to implant excellence.

Want to know more? Get in touch today.

To reserve your place or to find out more, visit http:// www.121implanteducation.co.uk/ or call 02074860000 .

\section{Over 800 attend virtual summit}

Align Technology, Inc. hosted a successful fourth edition of its Align GP Growth Summit. The virtual event drew together more than 20 guest speakers from around the world and was attended by over 800 delegates from Europe and beyond, who joined two days of lectures, break-out sessions, panel discussions and fireside chats.

Digital trends and innovation were central themes to this year's GP Growth Summit, where delegates had the opportunity to explore the latest consumer experience trends, futurism, marketing and branding, leadership skills and influence. Speakers also highlighted some of the latest digital tools to help practices thrive in challenging times, care for their patients more effectively and energise their teams.

In his keynote presentation, 'Digital Adaptation and Human Transformation', Anders Sörman-Nilsson, a global futurist, recommended that dentists invest in the digital touch points of their business, utilising the best technological know-how to complement their clinical expertise.

Reflecting on Align's role in introducing new digital innovations, Abhishek Ganguly, vice president sales, GP channel, core Europe stated: 'We are proud to be contributing to the growing uptake of digital tools amongst both consumers and doctors, particularly with our MyInvisalign App, which has been rolled out across 58 countries in the last year and is used by over 250,000 patients each month. We've also seen significant uptake of the Invisalign Virtual Appointment app and Invisalign Virtual Care tool, suggesting there is a clear appetite for these digital tools'.

The plenary sessions culminated in a fireside chat with keynote speaker Simon Sinek, a world-renowned optimist and motivational speaker based in the USA, whose work focuses on how to incite positive change to modify the way businesses and individuals think and behave. Sinek explored the subjects of leadership, purpose and how to bring your team together, leaving delegates with many tangible insights to draw on and apply in their own practices.

Raj Pudipeddi, chief innovation, product and marketing officer and senior vice president, Align Technology, concluded the event by explaining how Align Technology holds dental professionals at the centre of the company's business model.

\section{Win the decade's biggest business challenge}

The companies that succeed in the next 10 to 20 years will be those that embrace purpose and responsibility.

Helping to meet this challenge is The CSR Advantage by Mark Topley, a book created for those who are ready to step up and turn their responsibility into an advantage where everyone wins: people, planet, profit.

Mark is dedicated to helping business owners grow their leadership, teams and business with CSR [corporate social responsibility].

$\mathrm{He}$ is joined in his aspirations by a number of dental key opinion leaders, including author, speaker and business coach, Chris Barrow, and James Goolnik, author of Brush and owner of Bow Lane Dental.

Other keen advocates of Mark's approach to CSR are: global leader and innovation coach Alex Bell; business and leadership coach Kevin Rose; ADAM President Lisa Bainham; Justin Leigh, author of Inspire, Influence, Sell; and Colin Campbell, owner of The Campbell Clinic Group.

To get on the inside track, The CSR Advantage is available as an eBook from https://csrmadesimple.com/OrderPage at a special launch price of just $£ 4.99$ - an incredible offer for early adopters.

\section{Restoring strength and protecting patients}

Not all toothpastes are created equal. Arm \& Hammer Enamel Pro Repair baking soda toothpaste has been expertly engineered to provide a deep clean and help remineralise teeth.

Featuring Liquid Calcium technology, this refreshing mint toothpaste repairs surface enamel by filling accumulated damage, helping to smooth and re-strengthen the teeth. It is just one of several important steps to help patients restore their smiles and protect their oral health in the long term.

Demineralisation and remineralisation is a constant battle for patients with weakening enamel, Arm \& Hammer Enamel Pro Repair baking soda toothpaste can help restore lost strength and turn the tide.

For more information about the carefully formulated Arm \& Hammer toothpaste range, visit http://www.armandhammer. co.uk/or email: ukenquiries@churchdwight.com.

Arm \& Hammer oral healthcare products are available in store and online at Boots, Superdrug, Sainsbury's, Tesco, Asda and Morrisons throughout the UK. 